Manuscript submitted to:

Cement and Concrete Research

\title{
Mineralization Dynamics of Metakaolin-based Alkali-Activated Cements
}

Juan Pablo Gevaudan ${ }^{1}$, Kate M. Campbell ${ }^{2}$, Tyler J. Kane ${ }^{2}$, Richard K. Shoemaker ${ }^{3}$, Wil V. Srubar III ${ }^{1+}$

\begin{abstract}
This paper investigates the early-age dynamics of mineral formation in metakaolin-based alkali-activated cements. The effects of silica availability and alkali content on mineral formation were investigated via X-ray diffraction and solid-state ${ }^{29} \mathrm{Si}$ magic-angle spinning nuclear magnetic resonance at $2,7,14$, and 28 days. Silica availability was controlled by using either liquid- (immediate) or solid-based (gradual) sodium silicate supplements. Mineral (zeolitic) and amorphous microstructural characteristics were correlated with observed changes in bulk physical properties, namely shrinkage, density, and porosity. Results demonstrate that, while alkali content controls the mineralization in immediately available silica systems, alkali content controls the silica availability in gradually available silica systems. Immediate silica availability generally leads to a more favorable mineral formation as demonstrated by correlated improvements in bulk physical properties.
\end{abstract}

Keywords: D. Alkali-Activated Cement, D. Metakaolin, B. X-Ray Diffraction, C. Stability, Nuclear Magnetic Resonance (Nominated Keyword)

\section{Introduction}

The long-term durability of alkali-activated cements (AACs) depends on the stability of the aluminosilicate system, which is comprised of aluminosilicate minerals, mainly zeolites, and an amorphous phase that largely resembles a gel precursor to zeolite formation. It is well known that zeolites are thermodynamically metastable and can restructure into higher-stability zeolites over time. Similarly, the amorphous phase, which is less thermodynamically stable, has exhibited a potential to order into zeolitic minerals [1].

The formation and composition of amorphous phases, which is influenced by soluble silica, alkali content, and both curing time and temperature, dictate both the type and rate of potential zeolite formation [2] and influence the development of nano- and microstructures and influence both short-term material properties (e.g., compressive strength, porosity) and long-term durability [3]-[6] of AACs. Previous studies found that increasing soluble silica 
Manuscript submitted to:

Cement and Concrete Research

29 contents in alkali-activating solutions affect short- and long-term mineral dynamics by retarding zeolite formation

30 [4]. In addition, the presence of soluble silica species has been shown to impact reaction kinetics of aluminosilicate

31 precursors (e.g., metakaolin) that form amorphous phases [7]. For example, AACs with initially higher amorphous

32 contents have exhibited greater increases in compressive strength over time, due to a thermodynamic restructuring

33 into more ordered crystalline phases [3],[5].

34 Most previous studies have utilized pure liquid sodium silicate $(\mathrm{NaSi})$ solutions to provide immediately available

35 silica during alkali activation, while other researchers have investigated the utilization of recycled waste glass to

36 produce NaSi solutions [8], [9], [10]. Studies implementing waste-glass-derived liquid NaSi solutions in fly ash- and

37 slag-based AAC materials found no significant microstructural changes between such systems and those using

38 industrially produced NaSi solutions [11], [12]. In 2015, Bobirica, et al., [13] studied ground waste glass as a solid

39 NaSi supplement to fly ash- and fly ash/slag-based AACs. In this study, samples that included both liquid and solid

40 NaSi supplements demonstrated improved mechanical properties compared to those that were solely glass-

41 supplemented. While these studies demonstrate the impact of liquid versus solid NaSi supplements on bulk material

42 properties, no studies have mechanistically investigated the effect of silica availability and alkali content on the

43 mineralization dynamics of AACs.

\section{$44 \quad 1.2$ Scope of work}

45 The purpose of this study was to isolate and investigate the effects of time-dependent silica dissolution on early-age

46 mineral formation and stabilization in MK-based AACs. In this work, two MK-based systems were investigated,

47 namely (1) a system activated with a conventional sodium hydroxide ( $\mathrm{NaOH})$ and liquid sodium silicate (NaSi)

48 solution (rapid silica dissolution) and (2) a system activated with $\mathrm{NaOH}$ and a $\mathrm{NaSi}$ solution with additions of solid

49 waste glass (slow silica dissolution). The effect of Na:Si ratio on the time-dependent mineralization dynamics at the

50 nanoscale was explored in both systems using X-ray diffraction (XRD) and solid-state ${ }^{29}$ Si magic angle spinning

51 nuclear magnetic resonance (MAS-NMR). In addition, observable mineral dynamics were correlated with

52 macroscale changes in bulk material properties, namely shrinkage, density, and permeable porosity.

\section{2. Materials and Experimental Methods}

\section{$54 \quad 2.1$ Materials}

55 Metakaolin (MK) (MetaMax) was supplied by BASF Chemical Corporation (Georgia USA). Table 1 shows the 56 chemical composition of MK, which was obtained via inductively coupled optical emission spectrometry (ICP-OES) 
Manuscript submitted to:

Cement and Concrete Research

57 using a modified technique developed by [14]. Five $\mathrm{mL}$ of a 7:3 mixture of hydrochloric acid and hydrofluoric acid is combined with $2 \mathrm{~mL}$ of nitric acid and placed in the digestion tubes and heated to $95^{\circ} \mathrm{C}$ in a digestion block

59 (HotBlock by Environmental Express) for approximately two hours. Samples were then cooled and brought up to 50

$60 \mathrm{~mL}$ with a $1.5 \%$ by weight boric acid solution. The samples were then reheated to $95^{\circ} \mathrm{C}$ for about 15 minutes and

61 cooled for analysis. The samples were diluted 10x and analyzed with an ARL 3410+ ICP-OES. A blank and three

62 standards, which were made by accurately diluting certified standards, were used for calibration. The raw MK was

63 supplemented either with a reagent-grade sodium silicate ( $\mathrm{NaSi}$ ) solution supplied by Sigma Aldrich or waste soda-

64 lime glass. The chemical composition of the NaSi solution was determined to have a Na:Si weight modulus of 2.5,

65 as obtained via ICP-OES. Clear waste soda-lime glass was collected from a recycling waste stream at the University

66 of Colorado Boulder, soaked in a diluted nitric acid bath ( $5 \%$ acid by volume) for 12 hours, and washed thoroughly

67 with Alkanox cleaning agent to remove any acidity and residue. Glass was subsequently ground in mill capsules

68 with clean and well-packed yttrium-stabilized zirconium grinding beads (American Elements) at a rate of $0.2 \mathrm{~g} / \mathrm{min}$

69 using a McCrone micronizing mill. A No. 325 sieve was used to ensure a sub-45 $\mu \mathrm{m}$ particle size. The chemical

70 composition of the waste glass was measured with the same protocol as MK and is also shown in Table 1. Reagent-

71 grade $\mathrm{NaOH}$ pellets with $>97 \%$ chemical purity (No. S5881) were supplied by Sigma-Aldrich.

72 Table 1. Chemical composition of MK and waste glass in weight percent.

\begin{tabular}{lllllllll}
\hline (wt.\%) & $\mathbf{S i O}_{2}$ & $\mathbf{A l}_{\mathbf{2}} \mathbf{O}_{\mathbf{3}}$ & $\mathbf{C a O}$ & $\mathbf{S O}_{\mathbf{4}}$ & $\mathbf{F e}_{2} \mathbf{O}_{\mathbf{3}}$ & $\mathbf{K}_{\mathbf{2}} \mathbf{O}$ & $\mathbf{N a}_{\mathbf{2}} \mathbf{O}$ & $\mathbf{P}_{\mathbf{2}} \mathbf{O}_{\mathbf{5}}$ \\
\hline MK & $54 \%$ & $47 \%$ & $0.1 \%$ & $0.3 \%$ & $0.4 \%$ & $0.1 \%$ & $0.3 \%$ & $0.1 \%$ \\
Glass & $80 \%$ & $1.6 \%$ & $12 \%$ & $0.6 \%$ & $0.1 \%$ & $0.7 \%$ & $13 \%$ & - \\
\hline
\end{tabular}

73

\subsection{Experimental methods}

\section{$75 \quad 2.2 .1 \quad$ AAC sample preparation}

76 In this study, two classes of AACs were prepared with liquid-based $\mathrm{NaSi}(\mathrm{N})$ and solid-based, waste-glass-

77 supplemented, $\mathrm{NaSi}(\mathrm{G})$ solutions with varying molar concentrations - high (H), medium (M), and low (L) -

78 according to the prescribed mix-design parameters shown in Table 2. In these specific mixture formulations, liquid-

79 to-solid (L:S) ratios were $1.5 \mathrm{ml} / \mathrm{g}$ for G- samples and $2.25 \mathrm{ml} / \mathrm{g}$ for $\mathrm{N}$ - samples to ensure complete reaction during

80 mixing. Constant Si:Al ratio of 2.0 for all samples permitted explicit investigation of the effect of Na:Si ratio on the

81 mineralogical evolution in these two AAC systems.

$82 \mathrm{NaOH}$ solutions of different molar concentrations were prepared for each sample to obtain the specified $\mathrm{Na}: \mathrm{Si}$

83 ratios, as seen in Table 1, by dissolving $\mathrm{NaOH}$ pellets in deionized water under continuous agitation using a 
Manuscript submitted to:

Cement and Concrete Research

84 magnetic stir bar. Dissolution was performed in a temperature-controlled cold room $\left(4^{\circ} \mathrm{C}\right)$ to minimize evaporation

85 due to the exothermic nature of $\mathrm{NaOH}$ hydration. Once the $\mathrm{NaOH}$ solutions were prepared, the corresponding

86 amount of NaSi solution was added and the new solution was left to equilibrate for approximately two hours in the

87 cold room prior to mixing with N- samples. For the glass-based samples, waste glass was added as a solid silica supplement directly to the MK to prevent any glass dissolution prior to sample preparation.

89 Solids were mixed with their respective alkali-activating solutions to produce MK-based AACs that were silica-

90 supplemented with glass (G- samples) or liquid NaSi solutions (N- samples). All materials were mixed at room

91 temperature using a Waring PDM112 mixer. The mixing procedure consisted of one minute of initial mechanical

92 mixing, followed by one minute of hand mixing to ensure no material was unmixed on the sides of the vessel. Hand

93 mixing was followed by three minutes of additional mechanical mixing to ensure homogeneity.

94 Table 2. Sample classifications and mixture proportions for MK-based alkali-activated cements. Na:Si ratios were 95 varied by controlling the amount of $\mathrm{NaOH}$ used in preparation of the alkali-activating solution.

\begin{tabular}{|c|c|c|c|c|c|c|}
\hline \multirow[b]{3}{*}{ Mixes } & \multicolumn{6}{|c|}{ Constituent Materials } \\
\hline & \multicolumn{2}{|c|}{ Solids } & \multicolumn{2}{|c|}{ Alkali-Activating solution } & \multicolumn{2}{|c|}{ Important Parameters } \\
\hline & MK (g) & $\mathrm{SiO}_{2}$ Glass (g) & $\mathrm{NaSi}(\mathrm{ml})$ & $\mathrm{NaOH}(\mathrm{M})$ & $\mathrm{Si}: \mathrm{Al}$ & $\mathrm{Na}: \mathrm{Si}$ \\
\hline $\mathrm{NH}$ & 60 & - & 90 & 17 & 2.0 & 1.0 \\
\hline NM & 60 & - & 90 & 6 & 2.0 & 0.6 \\
\hline NL & 60 & - & 90 & 1 & 2.0 & 0.5 \\
\hline GH & 60 & 42.3 & - & 8 & 2.0 & 0.9 \\
\hline GM & 60 & 42.3 & - & 4 & 2.0 & 0.5 \\
\hline GL & 60 & 42.3 & - & 2 & 2.0 & 0.3 \\
\hline
\end{tabular}

Paste samples were cast in flat disk molds (diameter $5.2 \mathrm{~cm}$ ) for X-ray diffraction (XRD) and solid-state magic-

98 angle spinning nuclear magnetic resonance (MAS-NMR) spectroscopy and cylindrical molds (diameter $2.7 \mathrm{~cm}$,

99 height $10 \mathrm{~cm}$ ) for density, shrinkage, and permeable porosity testing. Samples were then cured inside hermetically

100 sealed plastic containers that maintained a $100 \%$ constant relative humidity condition. The constant-humidity

101 chamber was prepared according to ASTM E104 by placing a supersaturated salt solution of sodium phosphate

102 (Sigma Aldrich) inside the plastic containers. The containers were placed inside a Quincy forced-air laboratory oven

103 set to $60^{\circ} \mathrm{C}$. The temperature and humidity in each chamber was recorded using an EL-USB-2-LCD temperature and

104 humidity data logger from Lascar Electronics, respectively. Samples were allowed to cure for 2, 7, 14, and 28 days.

105 The containers were opened for 24 hours prior to the day of testing to allow samples to dry at $60^{\circ} \mathrm{C}$. Samples were

106 subsequently submerged in acetone (ACS-certified, $0.2 \% \mathrm{H}_{2} \mathrm{O}$, Fisher Scientific) for 15 minutes to halt hydration 
Manuscript submitted to:

Cement and Concrete Research

107 and then submerged in anhydrous ethanol (200 proof, $0 \% \mathrm{H}_{2} \mathrm{O}$, Decon Labs) for 15 minutes to halt alkali activation

108 prior to experimental testing [11].

$109 \quad$ 2.2.2 X-Ray Diffraction (XRD)

110 To determine mineralogy, flat disk samples were first crushed into a powder with a mortar and pestle. The powder

111 was then prepared for analysis using a modified method based on [15]. First, the powder was homogenized and split

112 into a representative aliquot. $1000 \pm 0.5 \mathrm{mg}$ of the powdered sample was mixed with $250 \pm 0.5 \mathrm{mg}$ of corundum

113 (American Elements) as an internal standard and added to a mill capsule containing clean, well-packed yttrium-

114 stabilized zirconium grinding beads. The mixture was subsequently ground using a McCrone micronizing mill with

$1154 \mathrm{~mL}$ ethanol for 5 minutes, generating particle sizes with $95 \%$ below $30 \mu \mathrm{m}$, measured via Malvern Mastersizer

1163000 laser diffraction system. A slurry of the mixture was created by adding approximately $25 \mathrm{~mL}$ of ethanol and

117 then dried overnight at $60{ }^{\circ} \mathrm{C}$ in a laboratory oven. The sample was then placed into a plastic scintillation vial with

118 three Delrin balls. $500 \mu \mathrm{L}$ of Vertrel cleaning agent (Miller-Stephenson) was added to the sample to generate

119 aggregates with random particle orientation. The scintillation vial was then mixed for ten minutes in a SK-L330 Pro

120 mechanical shaker. Finally, the samples were sieved through a $250 \mu \mathrm{m}$ mesh and packed into XRD analysis plates.

121 A Siemens D500 X-ray diffractometer was used to acquire diffraction patterns for all samples. Samples were

122 analyzed from 5 to 65 degrees $2 \theta$ using $\mathrm{Cu} \mathrm{K \alpha} \mathrm{X-ray} \mathrm{radiation} \mathrm{with} \mathrm{a} \mathrm{step} \mathrm{size} \mathrm{of} 0.02$ degrees and a dwell time of 2

123 seconds per step. Mineralogy was identified using Jade software (MDI, version 9) and the International Centre for

124 Diffraction Data (ICDD) 2003 database. Corundum was used to normalize peak heights between samples and to

125 align diffraction patterns.

126 2.2.3 Solid-state ${ }^{29}$ Si Magic Angle Spin-Nuclear Magnetic Resonance ( ${ }^{29}$ Si MAS-NMR)

127 Solid-state ${ }^{29}$ Si MAS-NMR spectra were acquired using a Varian INOVA 400 spectrometer (magnetic field 9.39 T;

128 operating frequency of $12.1 \mathrm{KHz}$ for $29 \mathrm{Si}) .{ }^{29} \mathrm{Si}$ chemical shifts were determined using the absolute spectrometer

129 frequency, calibrated such that the NMR signal from DSS (trimethylsilyl propane sulfonic acid, sodium salt)

130 appeared at $0.0 \mathrm{ppm}$. Calibrated chemical shifts were referenced to TMS within $1 \mathrm{ppm}$, resulting in a 5-6 ppm shift

131 upfield to the aluminosilicate NMR signal reference as reported by Klinowski, et al. [16]. The accuracy of DSS or

132 TMS referencing was verified via MAS ${ }^{1} \mathrm{H}$ NMR of DSS by setting the proton to $0.0 \mathrm{ppm}$ and using absolute

133 referencing for the ${ }^{29} \mathrm{Si}$ spectra. Thus, peak shifts using DSS and TMS as standards were verified and found to only

134 differ by $-1.5 \mathrm{ppm}$. For the acquisition of ${ }^{29} \mathrm{Si}$ spectra, samples were packed into $4 \mathrm{~mm}$ zirconia rotors sealed at either 
Manuscript submitted to:

Cement and Concrete Research

135 end with Teflon end plugs, and spun at $12.2 \mathrm{kHz}$ in a Varian probe equipped with a 4mm MAS spinning module 136 designed and manufactured by Revolution NMR, LLC (Fort Collins, CO). The spectra were acquired over 1024

137 scans using a pulse recycle delay of $5 \mathrm{~s}$, a pulse width of $4.5 \mu \mathrm{s}$ and an acquisition time of $20 \mathrm{~ms}$. Each spectrum

138 took on average approximately 90 minutes to acquire. Deconvolution of NMR data was performed using NUTS ${ }^{\circledR}$

139 software developed by Acorn NMR, Inc. All specimens were fully dehydrated to ensure that the presence of well-

140 resolved peaks in the spectra presented here indicate ordered silicon environments and not the presence of free

141 soluble silicon components in the pore solution.

$142 \quad$ 2.2.4 Dimensional shrinkage and density

143 Dimensional shrinkage was calculated as the percent difference in average diameter of samples prior to bulk

144 permeable porosity tests and initial diameter of the cylindrical molds. The diameters and heights of cylindrical

145 samples were measured using calipers. Using the measured volume and weights of samples from the bulk permeable

146 porosity the density for each sample was calculated.

$147 \quad$ 2.2.5 Bulk permeable porosity

148 Permeable porosities were measured using a vacuum-method (ASTM C1202). This method was selected due to its

149 proven higher efficiency when compared to other laboratory methods of calculating permeable porosity [17]. The

150 standard was modified by utilizing anhydrous ethanol in lieu of water to prevent any further alkali-activation or

151 reaction with water. Cylinder samples were first demolded after the 24-hour drying time. A Milwaukee 6-in

152 diameter angle grinder (9000 rpm) with a 3M polishing disc was used to grind the bottom and tops of cylinder

153 samples. Sample volumes were calculated by measuring the diameters and heights using calipers. Additionally,

154 samples were subjected to a vacuum of $508 \mathrm{~mm}$-Hg for 24 hours. The saturated surface dry (SSD) weight was

155 recorded using a Mettler Toledo PL $1502 \mathrm{E}$ scale after ethanol-vacuum immersion. Samples were then dried at $60^{\circ} \mathrm{C}$

156 for 24 hours and their oven-dry (OD) weights were recorded. Permeable porosity was calculated as the difference in

157 SSD mass and OD mass normalized by the density of ethanol $\left(0.803 \mathrm{~g} / \mathrm{cm}^{3}\right)$ all divided by the total sample volume.

158 3. Experimental Results and Discussion

159 3.1 Time-dependent mineralogy

160 Mineralogical data were acquired via XRD for all AAC pastes at four different curing ages. Table 3 describes the 161 main aluminosilicate minerals identified in at least one sample with their respective unit geometries, volumes, and 
Manuscript submitted to:

Cement and Concrete Research

162 densities, as determined by each reference standard. XRD patterns shown in Figure 1 and Figure 2 explicitly show

163 the presence or absence of those minerals in each $\mathrm{N}$ - and G- sample, respectively, at 2, 7, 14, and 28 days.

165 Table 3. Summary of aluminosilicate minerals of interest found via XRD with their corresponding symbols. Mineral 166 shapes, unit volumes, and densities have been obtained using the Jade5 zeolite database reference standard. Symbols 167 correspond to peak identification in Figure 1 and Figure 2.

\begin{tabular}{|c|c|c|c|c|c|c|c|}
\hline Mineral Name & Stoichiometry & Si:Al & Symbol & Shape & $\begin{array}{l}\text { Unit Volume } \\
\left(\AA^{3}\right)\end{array}$ & $\begin{array}{l}\text { Density } \\
\left(\mathrm{g} / \mathrm{cm}^{3}\right)\end{array}$ & Reference \\
\hline Zeolite ZSM-3 & $\mathrm{Na}_{1.88} \mathrm{Al}_{2} \mathrm{Si}_{2.77} \mathrm{O}_{9.48}$ & 1.39 & $\mathscr{C}$ & Hexagonal & 13,671 & 2.60 & [18] \\
\hline Zeolite $\mathrm{A}^{\text {(a) }}$ & $\mathrm{Na}_{2} \mathrm{Al}_{2} \mathrm{Si}_{1.71} \mathrm{P}_{0.48} \mathrm{O}_{8.6}-4.32 \mathrm{H}_{2} \mathrm{O}$ & $\sim 1.0$ & * & Cubic & 1,843 & 2.16 & [19] \\
\hline Zeolite Na-P & $\mathrm{Na}_{3.6} \mathrm{Al}_{3.6} \mathrm{O}_{3} \mathrm{Si}_{12.4} \mathrm{O}_{32}-14 \mathrm{H}_{2} \mathrm{O}$ & 3.44 & 0 & Tetragonal & 1,009 & 2.13 & [20] \\
\hline Sodalite & $\mathrm{Na}_{8} \mathrm{Al}_{6} \mathrm{Si}_{6} \mathrm{O}_{24}(\mathrm{OH})_{2}\left(\mathrm{H}_{2} \mathrm{O}\right)_{2}$ & 1.00 & $\nabla$ & Cubic & 703 & 2.46 & [21] \\
\hline Phillipsite-K & $(\mathrm{K}, \mathrm{Na})_{2}(\mathrm{Si}, \mathrm{Al})_{8} \mathrm{O}_{16}-4 \mathrm{H}_{2} \mathrm{O}$ & 1.00 & $\square$ & Monoclinic & 1,017 & 2.22 & [22] \\
\hline Zeolite P1 & $\mathrm{Na}_{6} \mathrm{Al}_{6} \mathrm{Si}_{10} \mathrm{O}_{32}\left(\mathrm{H}_{2} \mathrm{O}\right)_{12}$ & 1.67 & $\dagger$ & Tetragonal & 1,013 & 2.21 & [23] \\
\hline Faujasite-Na & $\mathrm{Na}_{1.84} \mathrm{Al}_{2} \mathrm{Si}_{4} \mathrm{O}_{11.92}-7 \mathrm{H}_{2} \mathrm{O}$ & 2.00 & + & Cubic & 15,550 & 2.02 & [24] \\
\hline Zeolite $5 \mathrm{~A}^{(\mathrm{b})}$ & $\mathrm{NaCaAl}_{3} \mathrm{Si}_{3} \mathrm{O}_{12.28} \mathrm{I}_{2.8}$ & 1.00 & $\#$ & Cubic & 1,856 & 3.24 & [25] \\
\hline
\end{tabular}

168 (a) XRD pattern corresponds to Zeolite A with partial replacement of Si-O bonds with P-O bonds, no significant framework change is reported in

169 [19]. ${ }^{(b)}$ XRD pattern corresponds to Zeolite 5A subjected to iodide absorption; no significant framework changes are reported in [25].

In general, the $\mathrm{N}$ - samples exhibit lower mineral diversity and broader peak patterns, indicating a higher

172 disordered mineral structure and/or smaller effective particle size in comparison to the G- samples. In addition, high

173 alkali content promoted early formation of zeolite mineral phases in both N- and G- systems. For example,

174 Faujasite-Na is formed after 2 days in NH samples (Figure 1a), while NL samples (Figure 1c) exhibit Faujasite-Na

175 formation after 14 days. Sodium carbonate (natrite, $\mathrm{Na}_{2} \mathrm{CO}_{3}$ ) was only present in the diffraction patterns of $\mathrm{N}$ -

176 samples, suggesting that the sodium in N- samples is more readily available to react with ambient carbon dioxide. 


\section{NH Samples (a)}
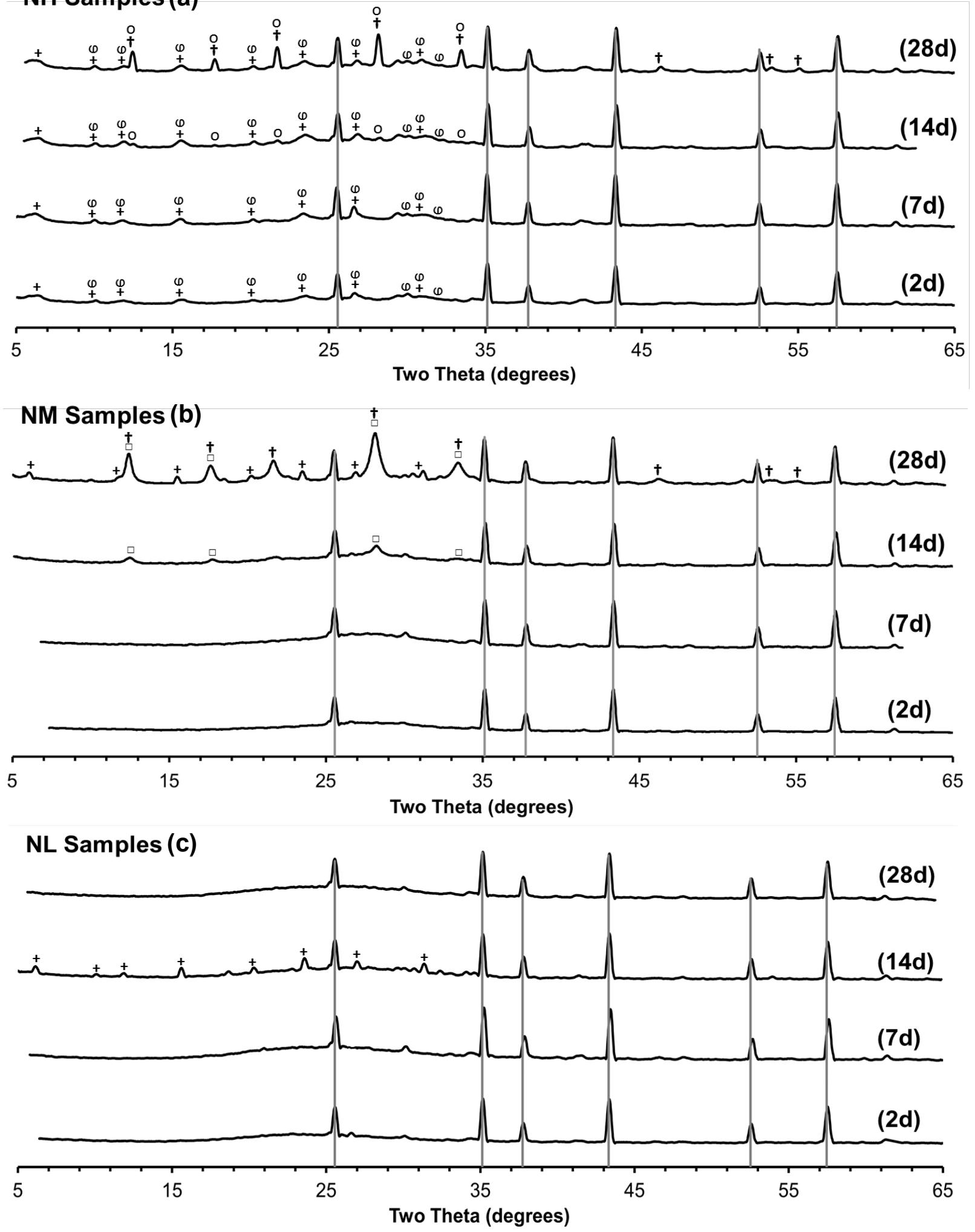

Figure 1. XRD spectra of $\mathrm{NH}$ (a), NM (b), and NL(c) samples at 2, 7, 14, and 28 days. Vertical grey lines correspond to the corundum internal standard. Mineral symbols are defined in Table 3. 


\section{GH Samples (a)}

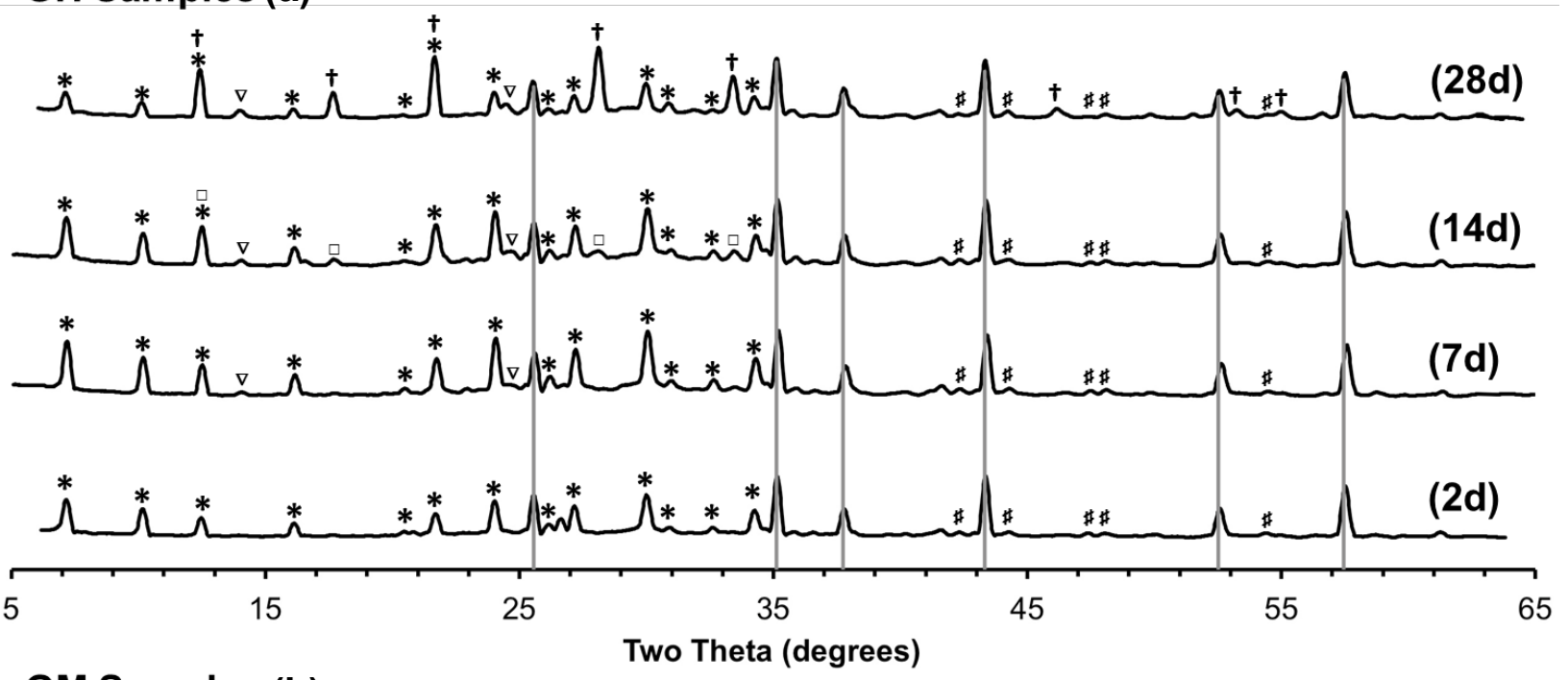

GM Samples (b)
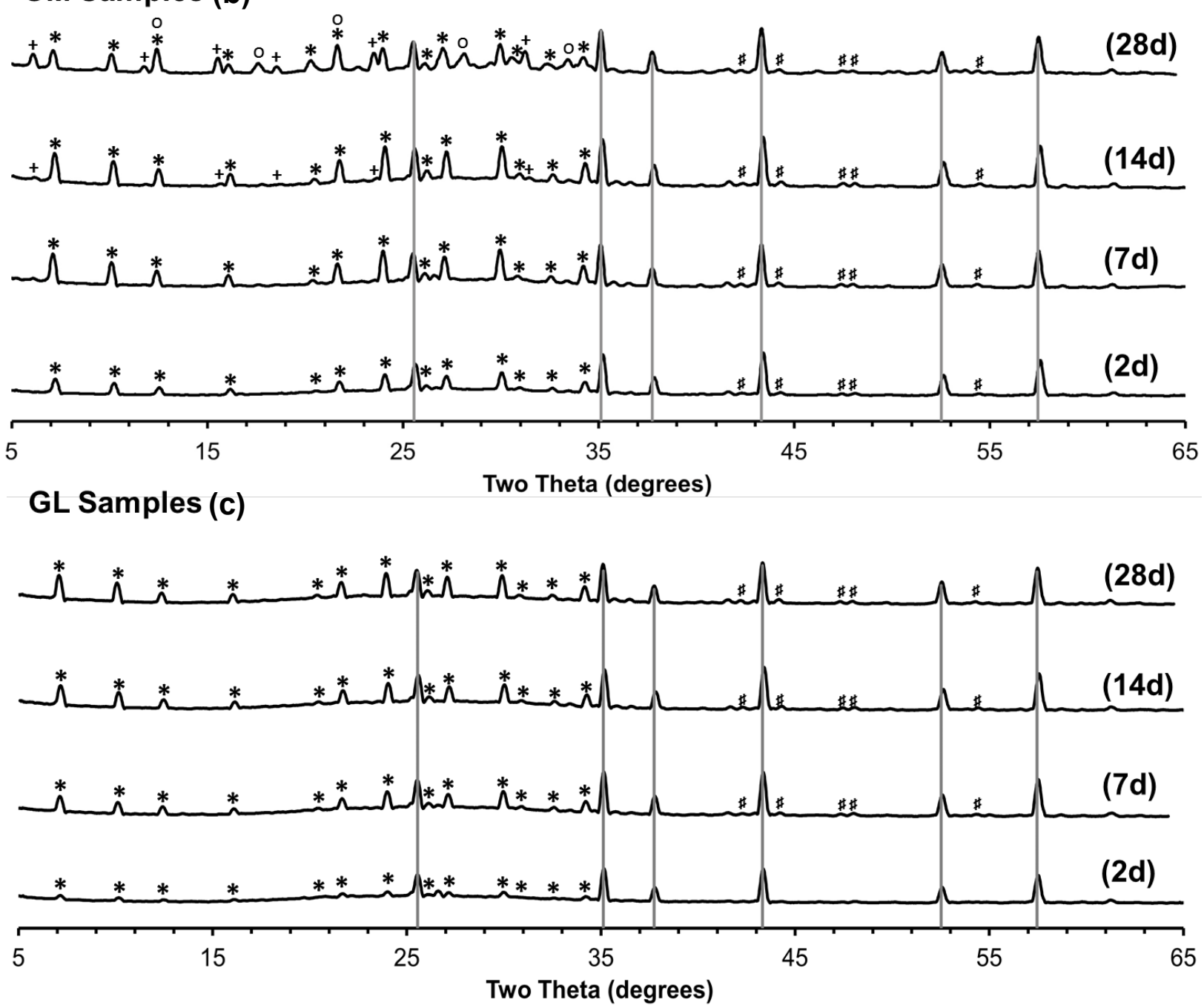

181 Figure 2. XRD spectra of GH (a), GM (b), and GL (c) samples at 2, 7, 14, and 28 days. Vertical grey lines correspond to the corundum internal standard. Mineral symbols are defined in Table 3. 
Manuscript submitted to:

Cement and Concrete Research

\subsubsection{Time-dependent mineralogy of $N$ - samples}

184 The observed mineral formation process for the NH samples was: Zeolite ZSM-3 + Faujasite-Na $\rightarrow$ Zeolite ZSM-3

185 + Faujasite-Na + Zeolite Na-P $\rightarrow$ Zeolite ZSM-3 + Faujasite-Na + Zeolite Na-P + Zeolite P1 (Figure 1a). The

186 observed mineral formation process for the NM samples was: Phillipsite-K $\rightarrow$ Faujasite-Na + Phillipsite-K +

187 Zeolite P1 (Figure 1b). Phillipsite-K is formed at 14 days, increasing in pattern intensity from day 14 to day 28 . At

18828 days, Phillipsite-K and Zeolite P1 are present. Both minerals have similar unit densities and volumes. NL

189 samples exhibited sparse mineral formation. The observed mineral formation process of the NL samples was:

190 Faujasite-Na $\rightarrow$ amorphous aluminosilicate (Figure 1c). The unexpected disappearance of Faujasite-Na at 28 days

191 might be due to a complete amorphization of the mineral at high Si:Na ratios, as previously reported in literature

$192[26]$.

193 Immediate silica availability coupled with a high sodium-alkali content yield early zeolite mineral formation. NH

194 samples exhibit early Faujasite-Na formation from an early age of 2 days through 28 days. Decreased sodium-alkali

195 content reduces mineral formation and retards Faujasite-Na formation, as seen in NM (Figure 1b) and NL (Figure

196 1c) samples. Faujasite-Na formation might be a result from the mineral stabilization of Zeolite ZSM-3, as previously

197 discussed in literature [18]. Zeolite ZSM-3, a low Si:Al mineral phase, was observed at 2 days in NH samples. The

198 formation of this zeolite may be the result of stabilization of an aluminum-rich gel, as described by Fernandez-

199 Jimenez and Palomo [27]. Such aluminum-rich phases were expected to develop first, given aluminum's higher

200 affinity for dissolution compared to that of silicon [7]. While Zeolite ZSM-3, a synthetic and relatively unstable

201 zeolite, has been reported to convert to Phillipsite (a more stable phase) [23], no Phillipsite was observed in the NH

202 samples under experimental conditions. Instead, Faujasite-Na is observed to form from Zeolite ZSM-3. Previous

203 literature has characterized this mineral stabilization pathway as a loss in the regularity in the cubo-octahedral layer

204 of Zeolite ZSM-3, resulting in the formation of Faujasite-Na [18]. Thus, Zeolite ZSM-3 may give rise to Faujasite-

$205 \mathrm{Na}$, a more stable, yet less dense, mineral [24].

206 High mineralization rates may degrade the bulk material properties of AACs, as is evident in the NM samples

207 from 14 to 28 days. All N- samples illustrate that, at early ages (2-14 days), increases in alkali content from low (-L)

208 to medium (-M) correspond to relatively little change in overall crystallinity. At later ages (28 days), however, the

209 proportions of crystalline-to-amorphous intensities (C:A Ratio) in both NL and NM samples differ. More

210 specifically, NL samples exhibit the lowest C:A Ratio of all N- samples at 28 days, while NM samples exhibit the 
Manuscript submitted to:

Cement and Concrete Research

211 highest C:A Ratio of all N- samples. As a result, NM samples have the highest change in C:A Ratio from 14 to 28

212 days, indicating a rapid crystallization of the sample during that time period. As discussed in Section 3.3, this abrupt

213 change in crystallinity is critical for understanding and, ultimately, controlling bulk material properties of AACs.

214 3.1.2 Time-dependent mineralogy of G- samples

215 The observed mineral formation process for the GH samples was: Zeolite A + Zeolite 5A $\rightarrow$ Zeolite A + Sodalite +

216 Zeolite $5 \mathrm{~A} \rightarrow$ Zeolite A + Sodalite + Zeolite $5 \mathrm{~A}+$ Phillipsite-K $\rightarrow$ Zeolite A + Zeolite P1 + Sodalite + Zeolite 5A

217 (Figure 2a). G- samples exhibited rapid crystallization as evident by consistently high C:A Ratios obtained in these

218 samples in comparison to the N- samples. For example, at 7 days, sodalite was formed in GH samples. At 28 days,

219 Zeolite P1 was also present, while Phillipsite-K was only observed at 14 days. The observed mineral formation

220 process for the GM samples was: Zeolite A + Zeolite 5A $\rightarrow$ Zeolite A + Faujasite-Na + Zeolite 5A $\rightarrow$ Zeolite A +

221 Faujasite-Na + Zeolite $\mathrm{P}+$ Zeolite 5A (Figure 2b). The intensity of the diffraction pattern for Zeolite A, an

222 aluminum-rich mineral, increases from day 2 to 14, while, at 28 days, the pattern yields to the formation of

223 geometrically distinct Zeolite P. Faujasite-Na is present in GM samples at both 14 and 28 days. While GL samples

224 exhibit sparse mineral formation, the following mineral formation process was observed: Zeolite $\mathrm{A} \rightarrow$ Zeolite A +

225 Zeolite 5A, (Figure 2c).

226 The results suggest that the gradual incorporation of silica into AAC frameworks (due to slow glass dissolution

227 over time) with high alkali content allows for the transformation of the cubic unit cell of Zeolite A into a monoclinic

228 (Phillipsite-K) and later tetrahedral (Zeolite P1) unit cells with successively decreasing dimensions. GH samples at

22914 days demonstrate changes in diffraction patterns attributed to decreased Zeolite A and formation of Phillipsite-K.

230 By 28 days, the diffraction pattern of Zeolite A is further reduced and, while Phillipsite-K is no longer observed,

231 Zeolite Na-P1 is present. These results may be indicative of successive solid-solid mineral transformations as

232 suggested by Ostwald's law of successive reactions [28]. The potentially deleterious effect of such solid-solid

233 transformation on bulk porosity is presented in Section 3.3.

234 The data demonstrate that gradual silica availability (G- samples) and alkali content affects the typology of

235 silicon-rich minerals and leads to increases in the Si:Al ratio of stabilized minerals over time. In general,

236 incorporation of silicon into silicon-rich minerals can lead to unit cell contractions and higher densities of precursor

237 minerals and amorphous gels. For example, in the GM samples, zeolites that formed from day 7 to day 28 exhibited

238 increases in Si:Al ratio. Zeolite A (Si:Al 1) was present on day 2, while Faujasite-Na (Si:Al 2) and Zeolite Na-P 
Manuscript submitted to:

Cement and Concrete Research

239 (Si:Al 3.44) are formed by day 28. Increases in Si:Al ratios of zeolites result in mineral phases with higher unit

240 densities and lower unit volumes at later ages compared to those at early ages. Silica availability might reach an

241 optimal level at medium alkali levels. GM samples form silicon-rich Faujasite-Na and Zeolite P. Increasing alkali

242 content hampers the formation of silicon-rich minerals and, instead, forms flexible framework Zeolite Na-P1.

243 Therefore, alkali content, in addition to silica availability, affects mineral variety and typology in gradually available

244 silica systems.

245 3.1.3 Comparative XRD analysis of $N$ - and $G$ - samples

246 Figure 3 summarizes the primary short-term mineral formation, transformation, and stabilization processes for each

247 sample investigated herein. Evidence suggests that the N- samples demonstrate early formation of silicon-rich

248 minerals, while G-samples tend to mineralize faster than N-samples, with most minerals possessing low-silicon

249 contents.

250 The previously proposed theory of nanocrystalline coexistence within the amorphous phase of AACs [29] can be

251 further supported by the herein observed time-dependent increase in crystallinity in all samples. In the N- samples,

252 pattern intensities increase with time. Aging allows for the gradual stabilization of the aluminosilicate framework

253 via thermodynamically favored crystalline mineral formation, as suggested by the observed increase in C:A Ratios,

254 presented in the Supplementary Material. The observed time-dependent increase in crystallinity might be due to

255 nucleation and growth of nanocrystals larger than $8 \mathrm{~nm}$, which would make them X-ray visible [30]. As explained

256 by Provis, et al., [33] the presence of zeolite nucleation sites dictates the mineralogy present in the microstructure of

257 AACs. Immediate silica availability via liquid NaSi solutions result in low mineral formations due to an increased

258 number of silica-competing zeolite nucleation sites. However, alkali hydroxide-activated cements (AACs without

259 liquid NaSi solutions) produce fewer zeolite nuclei, allowing larger crystal development. These crystals which are

260 unable to pack densely within the binder phase result in a more porous material [29]. In this study, gradually

261 available silica systems (G- samples), examples of alkali hydroxide-activated cements, expectedly exhibit higher

262 degrees of crystallization (higher C:A Ratios), compared to the N- samples. Unexpectedly, however, at medium

263 alkali levels (GM samples), the gradual availability of silica forms silicon-rich Zeolite-P (Si:Al ratio of 3.44), a

264 zeolite otherwise only present in NH samples. Also unexpectedly, Faujasite-Na in GM samples is formed earlier, at

26514 days, than in NM samples. Therefore, the gradually available silica at this medium alkali content enhances the

266 formation of silicon-rich zeolites. This behavior is unlike the alkali hydroxide-activated cement systems described in 
Manuscript submitted to:

Cement and Concrete Research

267 [33] as gradually available silica may reduce the silica competition between zeolite nucleation sites, resulting in 268 silicon-rich mineral formation.

269 Both gradual (G-) and immediate (N-) silica availability at medium and high sodium-alkali contents $(\mathrm{Na}: \mathrm{Si}>0.5)$

270 promote different formation patterns of gismondine-type framework zeolites, Zeolite P and Zeolite Na-P1, at later

271 ages. XRD patterns at 28 days demonstrate that Zeolite Na-P1 is evident in the GM samples, while Zeolite Na-P is

272 present in NM samples. At these same ages, both Zeolite Na-P1 and Zeolite P are present in NH samples, and only

273 Zeolite Na-P1 is present in GH samples. Investigating the effect of alkali content on the formation of these zeolites

274 in N- samples demonstrate that, as the alkali content decreases, only Zeolite Na-P1 is formed. The opposite trend is

275 observed in G- samples, where high alkali contents form Zeolite Na-P1 and medium alkali contents form Zeolite P.

276 Important differences exist between these minerals. For example, Zeolite P1 is flexible and can be readily distorted,

277 while Zeolite Na-P has a higher silica content and the highest possible gismondine-type symmetry [20], [23].

278 Therefore, as alkali content decreases in immediately available (N-) silica systems, favorable formation of flexible

279 gismondine-type framework zeolites occurs, while, in contrast, as alkali content decreases in gradually available (G-

280 ) silica systems, favorable formation of silicon-rich gismondine-type framework zeolites occurs. As discussed in

281 Section 3.3, different zeolite formation and stabilization pathways induce observable macrostructural changes to

282 bulk physical properties. 

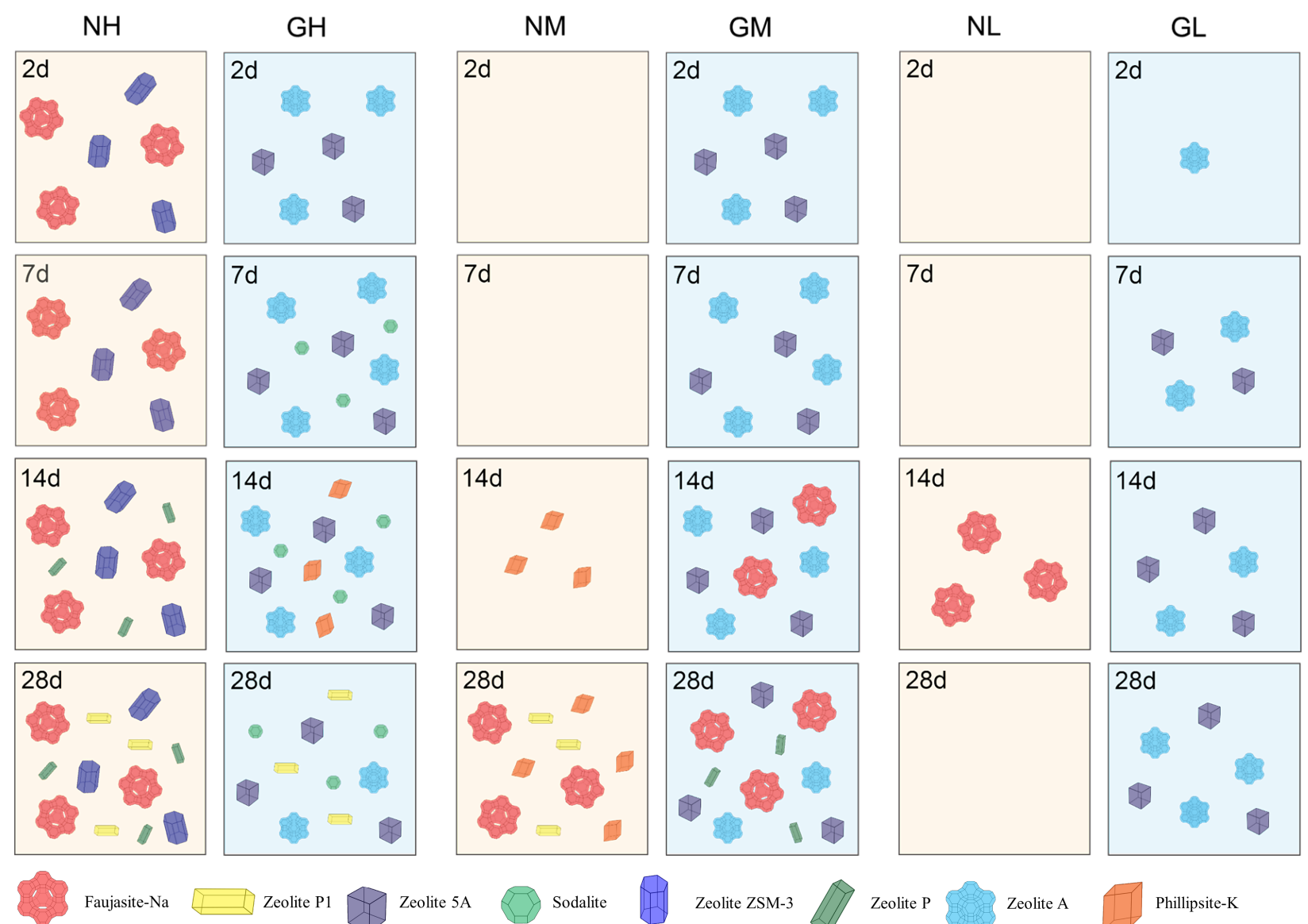

Zeolite P1 Zeolite $5 \mathrm{~A}$ Sodalite Zeolite ZSM-3 Zeolite P Zeolite A Phillipsite-K

Figure 3. Mineral dynamics as silica availability and alkali content vary over time based on observed XRD data for all samples. Quantity of minerals depicted is derived from relative intensity of XRD mineral patterns observed for each sample as time progressed.

\subsection{Solid-state ${ }^{29}$ Si MAS-NMR}

\subsubsection{MAS-NMR of metakaolin and ground waste glass}

291 The atomic silicon coordination of both raw metakaolin and ground waste glass, which were acquired via ${ }^{29} \mathrm{Si}$ solid-

292 sate MAS-NMR, is shown in Figure 4. Expectedly, the NMR spectrum for metakaolin is broad (band width: 100

293 ppm), indicating a highly disordered environment (Figure 4a). The main metakaolin peak at -104 ppm corresponds

294 to a predominate $\mathrm{Q}^{4}(1 \mathrm{Al})$ coordination. A secondary peak is observed at -91 ppm, which corresponds to $\mathrm{Q}^{4}(3 \mathrm{Al})$

295 atomic coordination. The presence of $\mathrm{Q}^{4}(3 \mathrm{Al})$ corresponds to nanostructures with high silicon contents, which, due

296 to silicon's slower rate dissolution compared to aluminum, can decrease the dissolution and precipitation kinetics of

297 the aluminosilicate material. The NMR signal for ground waste glass (Figure $\mathbf{4 b}$ ) was also characterized using a 
Manuscript submitted to:

Cement and Concrete Research

298 reference for alkali silicon glasses from the NMR handbook [31]. The main peak at $-92 \mathrm{ppm}$ is attributable to $\mathrm{Q}^{2}$ 299 coordination, while the secondary peak at -101 ppm is attributable to $Q^{3}$ coordination. ’

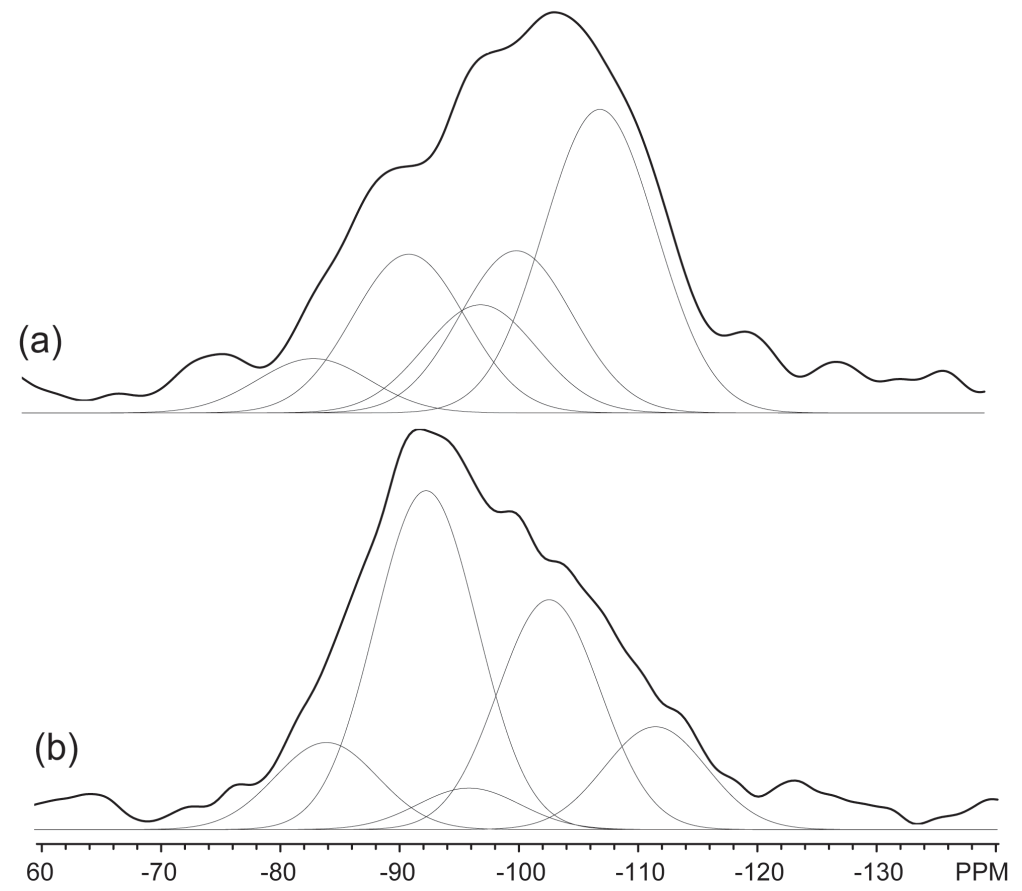

300 Figure 4. ${ }^{29} \mathrm{Si}$ solid-state MAS NMR spectra of both (a) metakaolin and (b) ground waste glass, showing 301 deconvoluted components below each spectrum. The main metakaolin peak at -104 ppm corresponds to a 302 predominate $\mathrm{Q}^{4}(1 \mathrm{Al})$ coordination. The main glass peak at $-92 \mathrm{ppm}$ is attributable to $\mathrm{Q}^{2}$ coordination in an 303 aluminosilicate system.

\subsection{2 ${ }^{29} \mathrm{Si}$ MAS-NMR of $N$ - and $G$ - samples}

306 Deconvolution of NMR spectra was carried out for all N- and G- samples using a modified methodology presented 307 by Duxson, et al. [32], to account for both disordered (amorphous) and ordered (mineral) silicon sites. Following 308 their aluminosilicate gel NMR-fitting methodology, broad Gaussian curves with fixed linewidths of 4-9 ppm were 309 fitted for all silicon-aluminum disordered sites with variable intensities $\left(\mathrm{Q}^{4}(\mathrm{nAl})\right)$. Fitted curves with linewidths less 310 than 4 ppm were deemed to have ordered silicon sites. Aluminosilicate amorphous material is characterized by a 311 complete distribution of $\mathrm{Q}^{4}(\mathrm{nAl})$, where $n$ varies from 0-4 [33]. Disordered peak positions were allowed to vary

312 within the ranges for each $\mathrm{Q}^{4}(\mathrm{nAl})$ coordination, as determined by [16] in a seminal study of aluminosilicate

313 structures. After disordered silicon sites were fitted, clear ordered silicon sites were fitted with line widths less than

$314 \quad 3-4 \mathrm{ppm}$ and a variable intensity to provide an appropriately summed curve fit. Calculation of internal Si:Al ratios

315 could not be compared with known chemical composition of each sample due to mineral formation affecting the 
Manuscript submitted to:

Cement and Concrete Research

316 silicon and aluminum contents of the amorphous material. The Si:Al ratio of the amorphous phase was estimated 317 using the following equation [33]:

$$
S i /_{A l}=\sum_{n=0}^{4} \mathrm{I}_{\mathrm{Si}(\mathrm{nAl})} / \sum_{n=0}^{4} \frac{n}{4} \mathrm{I}_{\mathrm{Si}(\mathrm{nAl})}
$$

319 where $I_{\mathrm{Si}(\mathrm{nAl})}$ is the intensity of each peak in the deconvoluted disordered ${ }^{29} \mathrm{Si}$ spectra for $n=0,1 \ldots 4$. While Si:Al

320 ratio is only appropriate to describe the amorphous material content, it is known that mineral formation or creation 321 of large quantities of $\mathrm{Si}(0 \mathrm{Al})$ will affect this ratio.

322 Both MK and glass precursors are consumed as a function of time and alkali content as evidenced by decreasing 323 silicon coordination sites within the amorphous phase. The percentages of silicon coordination sites present in the 324 amorphous phases of N- and G- samples at 7, 14, and 28 days are shown in Figure 5. The data show that increased 325 alkali content enhances dissolution of both MK and glass. Increased alkali content allows for a lower resonance 326 intensity at $-100 \mathrm{ppm}$, which is attributed to the main resonance of unreacted MK, as seen in Figure 4. N- samples 327 experience a decrease in the $\mathrm{Q}^{4}(1 \mathrm{Al})$ component $(\sim 100 \mathrm{ppm})$ of the spectra as alkali content increases, implying that 328 the signal resulting from MK has been largely diminished (Figure 5). The lower intensity of the $\mathrm{Q}^{4}(1 \mathrm{Al})$ component 329 could be a result of unreacted MK being almost completely consumed during the synthesis or disruption of the 330 network from dissolution processes [34]. Increase in C:A ratios, with alkali content further verify that both 331 unreacted and amorphous material are utilized for zeolite formation. Time is suspected to gradually dissolve the MK 332 precursor as $\mathrm{Q}^{4}(1 \mathrm{Al})$ sites are diminished from days 7 to 14 in NM and NL samples. This behavior is not observed 333 in NH samples potentially due to a high C:A ratio, see Supplementary Material, and early-age mineralization, 334 minimizing the observed decrease in $\mathrm{Q}^{4}(1 \mathrm{Al})$ sites (Figure 5). G-samples exhibit the similar trend increasing $335 \mathrm{Q}^{4}(1 \mathrm{Al})$ and C:A ratios as alkali content increase. Similar to the lower resonance intensity at -100ppm of MK, G336 samples experience an additional, but delayed, decrease in the resonance intensity at $-92 \mathrm{ppm}$, attributed to $\mathrm{Q}^{4}(3 \mathrm{Al})$ 337 sites of the AAC and $\mathrm{Q}^{2}$ sites of glass, see Figure 4. As seen in Figure 5, GM and GL samples reduce the 338 resonances at $-92 \mathrm{ppm}$ at later ages of 14 and 28 days. The lower intensity of the region could be a result from a 339 gradual dissolution process of glass at later ages due to lower alkali contents. Lower alkali contents are suspected to 340 achieve lower $\mathrm{pH}$ levels in the synthesis of AAC pastes, which would decrease the dissolution process of the glass. 341 Thus, the glass dissolution of GM and GL samples is controlled by a temperature dissolution of silica. This behavior 
Manuscript submitted to:

Cement and Concrete Research

342 is not observed in GH samples potentially due to a high C:A ratio, see Supplementary Material, and early-age mineralization, minimizing the observed decrease in $\mathrm{Q}^{4}(3 \mathrm{Al})$ sites, see Figure 5.

Reductions in aluminum-rich atomic sites, namely $\mathrm{Q}^{4}(4 \mathrm{Al})$ and $\mathrm{Q}^{4}(3 \mathrm{Al})$, and simultaneous increases in available silica coincided with formation of silicon-rich minerals in AAC samples (i.e., Faujasite-Na). Comparison of the $\mathrm{NMR} \mathrm{Q}^{4}(\mathrm{nAl})$ sites at 7 and 14 days (see Figure 5) demonstrate the shift of the N-samples toward aluminum-rich amorphous phases $\left(\mathrm{Q}^{4}(4 \mathrm{Al})\right)$ with increases in alkali content. The $\mathrm{G}$ - samples also exhibit the same trend, but generally exhibit higher percentages of $\mathrm{Q}^{4}(4 \mathrm{Al})$ than the $\mathrm{N}$ - samples. This finding is consistent with the observed reduction of silicon-rich minerals in these samples via XRD (see Figure 3). At low alkali levels (e.g., GL), however, this trend is not observed, because the mineralization of these samples is very low, as evidenced by the low C:A

351 Ratios of the XRD patterns. The GM samples, however, form silicon-rich Faujasite-Na and Zeolite P at later ages.

352 Together, these results suggest that the creation of silicon-rich minerals is dependent not necessarily on a high Si:Al 353 ratio, but rather on the availability of silica in conjunction with aluminum-rich atomic sites in the amorphous phase.

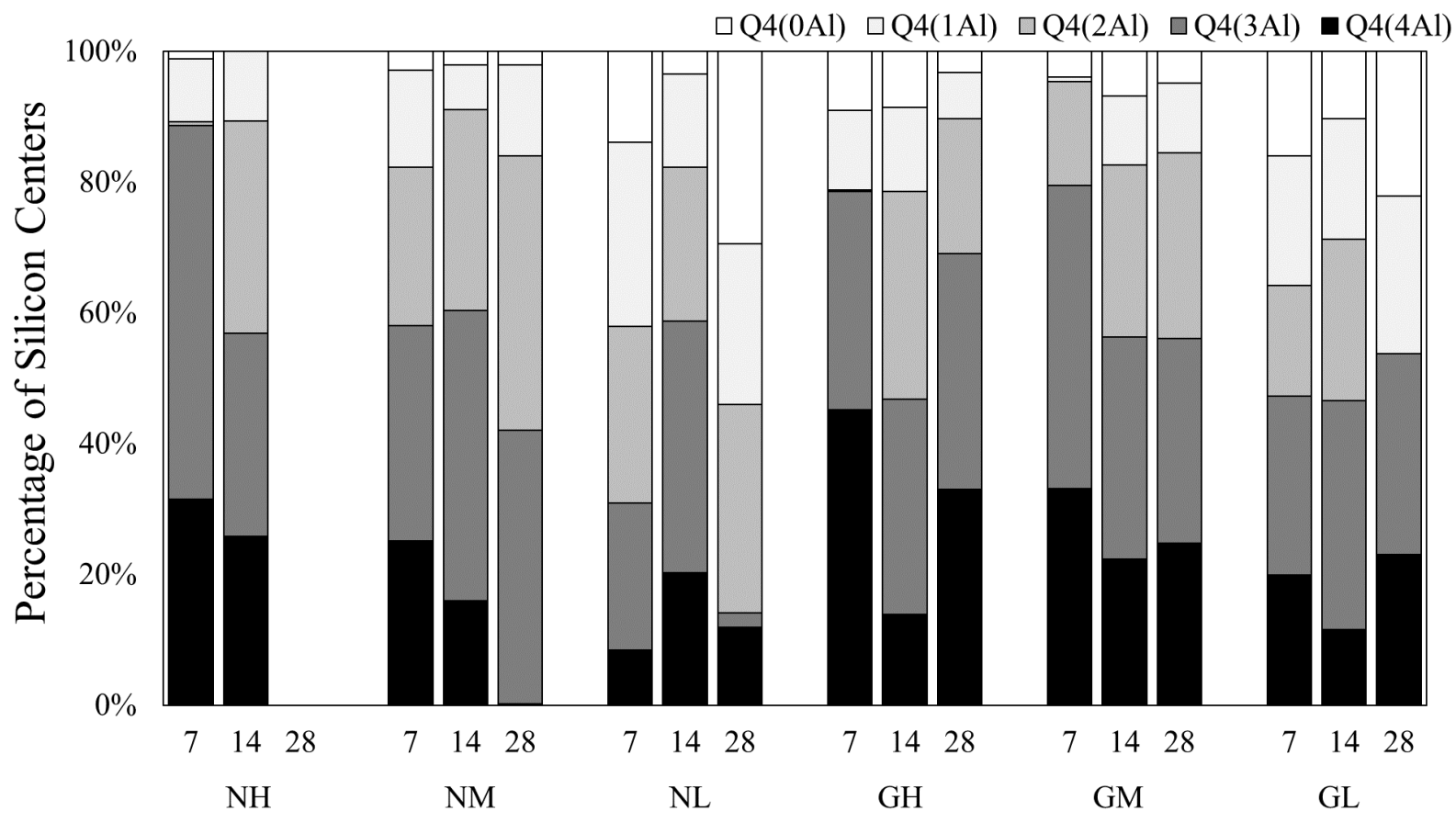

355 Figure 5. Fraction of silicon sites present in the amorphous phase as $\mathrm{Q}^{4}(4 \mathrm{Al}), \mathrm{Q}^{4}(3 \mathrm{Al}), \mathrm{Q}^{4}(2 \mathrm{Al})$, and $\mathrm{Q}^{4}(1 \mathrm{Al})$ for all samples as time varies: 7, 14 and 28 days. $\mathrm{NH}$ at 28 days is not presented as no amorphous phase was appropriately fitted according to described methodology. 
Manuscript submitted to:

Cement and Concrete Research

3.2.3 Disordered and Ordered ${ }^{29}$ Si atomic site distribution in $N$ samples

361 The presence of ordered silicon sites is indicated for all N- samples in Table $\mathbf{5}$, along with the corresponding total

362 deconvolution for all $\mathrm{Si}(\mathrm{nAl})$ sites. ${ }^{29} \mathrm{Si}$ spectra of $\mathrm{N}$ - samples were, to a large degree, characteristically disordered.

363 The increases of ordered silicon sites as both time and alkali content increase are consistent with observed XRD data

364 for these samples (see Figure 3). Deshielding of the silicon NMR signal is observed at high alkali contents from 7

365 days with more increases of $\mathrm{Q}^{4}(4 \mathrm{Al})$ and $\mathrm{Q}^{4}(3 \mathrm{Al})$ sites than medium and low alkali content samples $(\mathrm{NH}>\mathrm{NM}>$

$366 \mathrm{NL})$. Similarly, ordered silicon sites follow a similar trend with ordered $\mathrm{Q}^{4}(4 \mathrm{Al})$ being the only ordered atomic

367 arrangement in the NH sample. This opposite trend is supported by low alkali samples, which have a higher

368 proportion of shielded silicon sites, $\mathrm{Q}^{4}(2 \mathrm{Al}), \mathrm{Q}^{4}(1 \mathrm{Al})$, and $\mathrm{Q}^{4}(0 \mathrm{Al})(\mathrm{NL}>\mathrm{NM}>\mathrm{NH})$, as shown in Figure 5.

Table 5. ${ }^{29} \mathrm{Si}$ NMR signal deconvolution for $\mathrm{AAC}$ samples at different curing ages. $\mathrm{Q}_{\mathrm{n}}$ represents non-tetracoordinated units.

\begin{tabular}{|c|c|c|c|c|c|c|c|c|}
\hline & Age & $\mathrm{Q}_{\mathrm{n}}$ & $\mathrm{Si}(4 \mathrm{Al})$ & $\mathrm{Si}(3 \mathrm{Al})$ & $\mathrm{Si}(2 \mathrm{Al})$ & $\mathrm{Si}(1 \mathrm{Al})$ & $\mathrm{Si}(0 \mathrm{Al})$ & Si:Al \\
\hline \multirow[t]{3}{*}{$\mathrm{NH}$} & 7 Day & $18 \%$ & $37 \% \%^{(a)}$ & $38 \%$ & $0 \%$ & $6 \%$ & $1 \%$ & 1.30 \\
\hline & 14 Day & $2 \%(a)$ & $39 \%(a)$ & $31 \%(a)$ & $21 \%$ & $7 \%$ & $0 \%$ & 1.47 \\
\hline & 28 Day & $29 \%{ }^{a)}$ & $28 \%{ }^{(b)}$ & $13 \%(b)$ & $15 \%(b)$ & $10 \%(b)$ & $5 \%{ }^{(b)}$ & 1.49 \\
\hline \multirow[t]{3}{*}{ NM } & 7 Day & $5 \%$ & $24 \%$ & $31 \%(c)$ & $23 \%$ & $14 \%$ & $3 \%$ & 1.52 \\
\hline & 14 Day & $1 \%$ & $16 \%$ & $44 \%(c)$ & $30 \%$ & $7 \%$ & $2 \%$ & 1.51 \\
\hline & 28 Day & $2 \%$ & $1 \%{ }^{(a)}$ & $40 \%(a)$ & $43 \%(a)$ & $13 \%(a)$ & $2 \%$ & 1.79 \\
\hline \multirow[t]{3}{*}{ NL } & 7 Day & $1 \%$ & $8 \%$ & $22 \%$ & $27 \%$ & $28 \%$ & $14 \%$ & 2.18 \\
\hline & 14 Day & - & $20 \%$ & $38 \%$ & $24 \%$ & $14 \%$ & $3 \%$ & 1.55 \\
\hline & 28 Day & - & $12 \%$ & $2 \%$ & $32 \%$ & $25 \%$ & $29 \%$ & 2.81 \\
\hline \multirow[t]{3}{*}{$\mathrm{GH}$} & 7 Day & $8 \%$ & $24 \%(a)$ & $59 \%(a)$ & $0 \%$ & $5 \%$ & $4 \%$ & 1.36 \\
\hline & 14 Day & $9 \%$ & $25 \%(a)$ & $55 \%(a)$ & $6 \%$ & $3 \%$ & $2 \%$ & 1.73 \\
\hline & 28 Day & - & $52 \%(a)$ & $26 \%$ & $15 \%$ & $5 \%$ & $2 \%$ & 1.39 \\
\hline \multirow[t]{3}{*}{ GM } & 7 Day & $9 \%(a)$ & $21 \%$ & $58 \%(a)$ & $10 \%$ & $0 \%$ & $2 \%$ & 1.32 \\
\hline & 14 Day & $5 \%(a)$ & $14 \%$ & $52 \%(a)$ & $17 \%$ & $7 \%$ & $4 \%$ & 1.57 \\
\hline & 28 Day & $11 \%^{(a)}$ & $17 \%$ & $43 \%(a)$ & $19 \%$ & $7 \%$ & $3 \%$ & 1.54 \\
\hline \multirow[t]{3}{*}{ GL } & 7 Day & - & $16 \%$ & $32 \%(a)$ & $14 \%$ & $16 \%$ & $22 \%$ & 1.86 \\
\hline & 14 Day & - & $10 \%$ & $37 \%(a)$ & $22 \%$ & $17 \%$ & $13 \%$ & 1.83 \\
\hline & 28 Day & - & $24 \%(a)$ & $38 \%{ }^{(a)}$ & $0 \%$ & $20 \%$ & $18 \%$ & 1.93 \\
\hline
\end{tabular}

${ }^{\mathrm{c}}$ Peaks of high intensity, yet broad linewidth (8 ppm), relating to ordered silicon coordination. 
Manuscript submitted to:

Cement and Concrete Research

377 resonance frequencies $\left(\mathrm{Q}^{4}(2,1 \mathrm{Al})\right)$ to a greater degree than medium alkali samples $\left(\mathrm{Q}^{4}(3,2 \mathrm{Al})\right)$. As a result there is a 378 greater proportion of Si-O-Si bonds in the amorphous content of the NH at 14 days. The increase of silicon in an

379 aluminosilicate framework decreases its thermodynamic stability, which leads to an increased propensity to form

380 zeolites of higher thermodynamic stability [28]. This propensity is affirmed by the observed increase in C:A Ratios

381 and the formation of silicon-rich minerals, such as Faujasite-Na, as previously discussed.

382 Limitations of NMR deconvolution of aluminosilicate gels are evident in samples that have varying degrees of

383 mineralization. For example, NMR spectra of medium alkali content samples demonstrate a high intensity, yet

384 broad, peak at $\mathrm{Q}^{4}(3 \mathrm{Al})$ (8 ppm line width), suggesting a disordered environment. Such a large line width cannot be

385 confidently deconvoluted using a Gaussian distribution and be classified as a completely disordered atomic

386 environment. While the Duxson, et al., [32] NMR deconvolution methodology might seem applicable, XRD data

387 reveals the presence of Phillipsite-K. Due to probable eclipse of ordered signals within disordered signals, this

388 seemingly amorphous system is, in actuality, a composite system of both mineral and amorphous content. Therefore,

389 the results from this study affirm that this methodology is currently limited only to systems of gel aluminosilicates

390 with no significant mineral formation. Further evidence is provided by NL samples, whose respective disordered

391 sites shift toward higher silicon contents. This shift occurs in tandem with the development of silicon-rich minerals

392 (Faujasite-Na) at 14 days as identified by XRD. However, the highly disordered arrangement of NL samples has not

393 allowed for the clear distinction of an ordered peak within the NMR spectra.

394 The NH signal corresponded to a highly ordered system (2.5 ppm line width), which limited the analysis of an

395 amorphous phase. Deshielding of silicon's magnetic resonances is observable in NH samples as seen by an increase

396 in $\mathrm{Q}^{4}(4 \mathrm{Al})$ sites and $\mathrm{Q}_{\mathrm{n}}$ sites (see Table 5). $\mathrm{Q}_{\mathrm{n}}$ sites correspond to silicon monomers, dimers, and trimers [35]. The

397 occurrence of this deshielding is most significant in NH samples and thus, it is potentially attributable to high alkali

398 content present in the system. As discussed in Duxson, et al., [32] this deshielding might be due to the effects of

399 high alkali content or the high energy penalty associated with the possible formation of Al-O-Al bonds.

$400 \quad$ 3.2.4 Disordered and Ordered ${ }^{29}$ Si atomic sites distribution in $G$ - samples

401 The presence of ordered silicon sites is indicated for all G- samples are also shown in Table 5. As previously

402 discussed, in gradually available silica systems, the formation of silicon-rich minerals is largely determined by alkali

403 content, as was evidenced by the silicon-rich minerals only observed in the GM samples. Between 14 and 28 days,

404 GM samples formed silicon-rich Zeolite $\mathrm{P}$ and Faujasite-Na at high crystallization rates, as determined by the abrupt 
Manuscript submitted to:

Cement and Concrete Research

405 changes in C:A Ratios in that timeframe, which was accompanied by minimal changes to the distribution of $\mathrm{Q}^{4}(\mathrm{nAl})$

406 sites in the amorphous phase between 14 and 28 days (see Figure 5). This result is expected, given that the creation

407 of Faujasite-Na and other silica rich minerals partly consumes $\mathrm{Q}^{4}(4 \mathrm{Al})$ and $\mathrm{Q}^{4}(3 \mathrm{Al})$ sites of the amorphous phase, as

408 previously discussed. This behavior is also observed in GH samples, which exhibited a decrease in silicon rich

409 atomic sites, namely $\mathrm{Q}^{4}(2 \mathrm{Al})$, as the amorphous and mineral phase is consumed in the formation of Zeolite P1,

410 another silicon-rich mineral, at 28 days. This result is important as higher alkali contents (Na:Si $\sim 1.0)$ demonstrate a

411 highly dynamic amorphous and crystalline phase than lower alkali contents (Na:Si $\sim 0.5)$ in samples with gradual

412 silica availability. As alkali content decreases, the silicon content of the ordered and disordered sites increase from

41314 to 28 days. For example, GH samples have a higher content of $\mathrm{Q}^{4}(4 \mathrm{Al})$ sites, while GM and GL retain a higher

414 content of $\mathrm{Q}^{4}(3 \mathrm{Al})$ sites (see Figure 5 and Table 5). As a result, gradually available silica spares the solid-solid

415 transformation of the amorphous phase into crystalline zeolites.

416 As previously discussed, the GM samples were the only samples to form Faujasite-Na and also the only G-

417 samples to exhibit an ordered $\mathrm{Q}_{\mathrm{n}}$ formation. The highly deshielded $\mathrm{Q}_{\mathrm{n}}$ sites are potentially associated with the

418 formation of silicon-rich zeolites, such as Faujasite-Na, as also seen in the NH samples and, to a lesser extent, the

419 NM samples. This trend is however not observed in NL samples at 14 days, which could be due to an eclipsing of

420 the major disordered silicon sites over those ordered or complete amorphization of Faujasite-Na minerals.

\subsection{Bulk physical properties}

\section{$422 \quad 3.3 .1$ Density and dimensional shrinkage}

423 The densities and dimensional shrinkages of the N- and G- samples are shown below in Table 6. High density and

424 shrinkage values were achieved either via formation of Faujasite-Na at steady rates or formation of a prominent

425 amorphous phase. NH samples, for example, which demonstrate early formation of Faujasite-Na (see Figure 3) and

426 with a gradual increase in C:A Ratio from 7 to 28 days, also exhibited the highest density of all samples. In contrast,

427 NL samples, which demonstrated no mineral formation at 28 days and low C:A ratios, exhibited the second-highest

428 density and the highest shrinkage at 28 days, which can be attributed to its prominent amorphous phase. ${ }^{29} \mathrm{Si}$ NMR

429 analysis proves that NL samples have a silicon-rich amorphous phase $\left(\mathrm{Q}^{4}(0 \mathrm{Al}), \mathrm{Q}^{4}(1 \mathrm{Al})\right)$, which also exhibits a high

430 density value, see Figure 5. Silicon-rich phases have a greater water content, which would allow greater shrinkage

431 of the samples and densification [36]. 
Manuscript submitted to:

Cement and Concrete Research

432 Low density and shrinkage values were achieved via rapid and increased formation of minerals. The rapid crystallization of NM samples from 14 to 28 days, as indicated by an increase in C:A Ratio exhibit the lowest

434 dimensional shrinkage (2\%) and a low density. In general, G- samples exhibit high CA Ratios, indicating high

435 degrees of mineralization. Analysis of the ${ }^{29} \mathrm{Si}$ NMR spectra of GL samples reveals that these samples also have a greater content of silicon-rich amorphous phase $\left(\mathrm{Q}^{4}(0 \mathrm{Al}), \mathrm{Q}^{4}(1 \mathrm{Al})\right)$, than their $\mathrm{G}$ - sample counterparts. As a result,

437 GL samples exhibit greater shrinkage than GM and GH samples. However, the shrinkage values are very low 438 compared to N-samples, most probably due to the high crystallization (high C:A Ratios) observed in the G- samples.

Table 6. Density at 28 days and dimensional shrinkage of AAC samples at 7, 14, and 28 days. N/A denotes that no data was able to be collected for this sample due to incomplete curing.

\begin{tabular}{lllll}
\hline \multirow{2}{*}{ Sample } & Density $\left(\mathrm{g} / \mathrm{cm}^{3}\right)$ & \multicolumn{2}{l}{ Shrinkage } & \\
\cline { 3 - 5 } & & 7 Days & 14 Days & 28 Days \\
\hline $\mathrm{NH}$ & 1.62 & $11 \%$ & $4 \%$ & $15 \%$ \\
$\mathrm{NM}$ & 0.77 & $\mathrm{~N} / \mathrm{A}$ & $2 \%$ & $2 \%$ \\
$\mathrm{NL}$ & 1.18 & $16 \%$ & $11 \%$ & $16 \%$ \\
\hline $\mathrm{GH}$ & 0.72 & $1 \%$ & $1 \%$ & $1 \%$ \\
$\mathrm{GM}$ & 0.74 & $1 \%$ & $1 \%$ & $3 \%$ \\
$\mathrm{GL}$ & 0.59 & $4 \%$ & $2 \%$ & $3 \%$ \\
\hline
\end{tabular}

\subsubsection{Bulk permeable porosity}

444 Figure 6 shows the permeable porosities obtained at 14 and 28 days for all samples. NH samples exhibited the

445 lowest porosity, while GH exhibits the highest porosity of all samples investigated herein. In general, immediate

446 silica availability allows for the retardation of the rate of mineral formation and, thus, achieves favorably lower

447 permeable porosities over time in the range of 21\%-62\%. Gradual silica availability, however, promotes higher crystallization and corresponding increases in permeable porosity, as evidenced by the G- samples.

As discussed, gradual silica availability allows for solid-solid transformations of zeolite minerals, which can

450 lead to higher permeable porosity. For example, in the GH samples, the probable transformation of the cubic unit 451 cell of Zeolite A into a monoclinic (Phillipsite-K) and, later, a tetrahedral (Zeolite P1) unit cell in the GH samples

452 (see Figure 3) correlates to a 6\% increase in permeable porosity. While the mechanism of such solid-solid

453 transformation has not been explicitly studied herein, the observed changes are in agreement with Ostwald's law of

454 successive reactions [28]. The increased porosity of GH samples is expected from the abrupt change in C:A Ratio

455 observed from 14 and 28 days. 
Manuscript submitted to:

Cement and Concrete Research

456 Mineralization rate and mineral typology suggest a possible direct influence on the bulk permeable porosities of 457 the AACs investigated herein. The presence of Phillipsite-K and Zeolite P1 (gismondine-type frameworks) in the

458 GH and NM samples coincides with increases in permeable porosity. In addition, the formation of Faujasite-Na and 459 high amorphous contents are known to decreases porosity in AACs [1]. Expectedly, the GM samples experience a

460 slight decrease in porosity that can be attributed to late-age Faujasite-Na formation. The early formation of

461 Faujasite-Na, however, coincides with decrease permeable porosity, as observed for NH, NM, NL and GM samples.

462 Data from the NH and NH samples provide evidence that bulk physical properties can be affected by mineral

463 formation and stabilization pathways. Crystallization rates of AAC paste are important for bulk properties. The NH

464 samples exhibit a much more gradual increase in relative C:A phase intensities, yielding a decrease in permeable

465 porosity. Thus, the high alkali content in NH samples allows for higher crystal phase diffraction intensities in

466 proportion to their bulk amorphous signal at an early age, with not much change at later days. Contrastingly, NM

467 samples exhibit a change of 0.30 from 14 to 28 days, which relates to a $9 \%$ increase in permeable porosity. The

468 steady crystallization behavior most exhibited by NH samples may be critical to minimizing permeable porosity

469 development.

470 As expected, high shrinkage correlates to a dense material due to a tightening of the matrix, which allows for

471 reduction in porosity. As observed in the data, Table 6 and Figure 6, NH and NL samples have both the highest

472 shrinkage and density, which correlate to both decreases in porosity from 14 to 28 days. The shrinkage in both

473 samples can be due to loss of water from a silicon rich amorphous phase composed of $\mathrm{Q}^{4}(0 \mathrm{Al})$ and $\mathrm{Q}^{4}(1 \mathrm{Al})$, as

474 evident in the NL sample (Figure 5). ${ }^{29} \mathrm{Si} \mathrm{NMR} \mathrm{deconvolution} \mathrm{analysis} \mathrm{did} \mathrm{not} \mathrm{discern} \mathrm{a} \mathrm{distinct} \mathrm{amorphous} \mathrm{phase}$

475 in the NH samples at 28 days, yet presence of $\mathrm{Q}^{\mathrm{n}}$ sites might be indicative of highly deshielded silicon sites in the

476 amorphous phase. Furthermore, the presence of an amorphous phase can be deduced due to a high shrinkage value

477 as observed in the NL samples. 


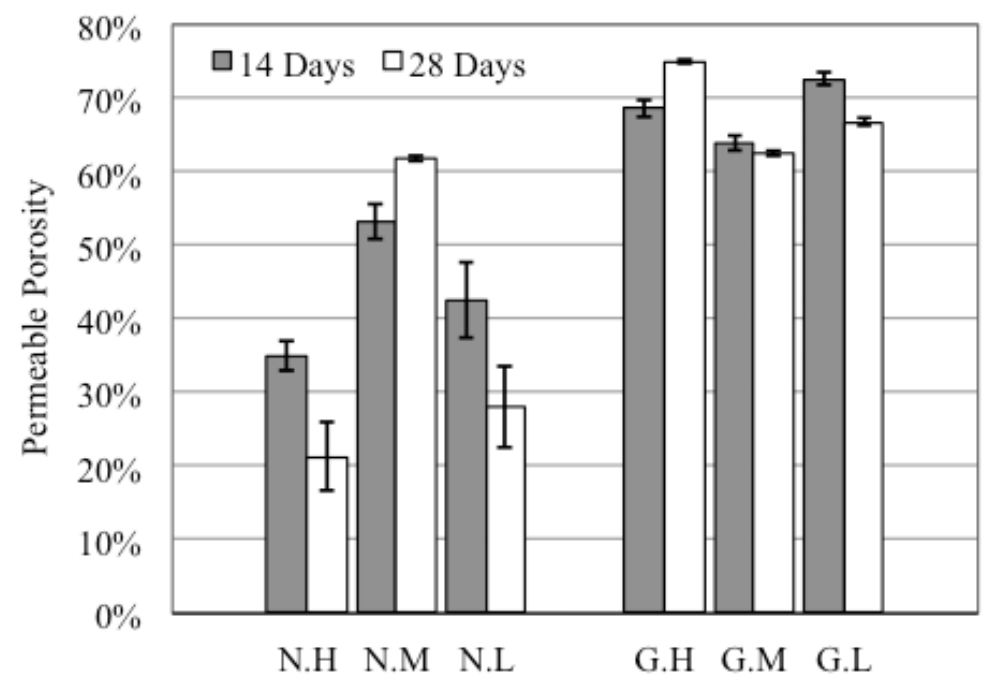

Figure 6. Bulk permeable porosities of G- and N- samples at 14 and 28 days.

\section{Conclusions}

This study isolated and investigated the effects of time-dependent silica dissolution on early-age mineral formation and stabilization in MK-based AACs. The effects of immediate and gradual silica availability and alkali content (Na:Si ratio) on the mineralization dynamics at the nanoscale was explored using XRD and solid-state ${ }^{29} \mathrm{Si}$ MASNMR and correlated with macroscale changes in bulk physical properties.

The results demonstrate that mineral formation and stabilization pathways in MK-based AACs is dependent not only on Si:Al ratio, but also on both silica availability and alkali content. The time-dependent XRD patterns and NMR spectra, in concert with characterization of bulk physical properties, show that these mineralization and stabilization pathways can have adverse effects on bulk physical properties. For example, the early formation and growth of silicon-rich minerals or the existence of a predominant silicon-rich amorphous phase coincided with reductions in bulk permeable porosity. However, late-age crystallization (amorphous-to-crystalline) and solid-solid (crystalline-to-crystalline) mineralogical transformations, which were observed, both led to increases in porosity. These results demonstrate the importance of understanding and, ultimately, controlling the mineral formation and stabilization dynamics in MK-based AAC systems.

\section{Acknowledgments}

This research was made possible by the Department of Civil, Environmental, and Architectural Engineering, the College of Engineering and Applied Sciences, and the Sustainable Infrastructure Materials Laboratory (SIMLab) at 
Manuscript submitted to:

Cement and Concrete Research

502 the University of Colorado Boulder, with partial support from the National Science Foundation (Award No. CBET-

503 1604457). The collaboration with the United States Geological Survey, the Department of Chemistry, and the

504 Nanocharacterization Laboratory is gratefully acknowledged. This work represents the views of the authors and not

505 necessarily those of the sponsors. Any use of trade, firm, or product names was for descriptive purposes only and

506 does not imply endorsement by the U.S. government. This draft manuscript is distributed solely for purposes of

507 scientific peer review. Its content is deliberative and predecisional, so it must not be disclosed or released by

508 reviewers. Because the manuscript has not yet been approved for publication by the U.S. Geological Survey

509 (USGS), it does not represent any official USGS finding or policy.

$510 \quad$ 6. References

511 [1] A. Palomo, M. T. Blanco-Varela, M. L. Granizo, F. Puertas, T. Vazquez, M. W. Grutzeck Chemical

512 stability of cementitious materials based on metakaolin. Cem. Concr. Res. 29(7) (1999) 997-1004.

513 [2] M. Criado, A. Fernández-Jiménez, A. Palomo. Alkali activation of fly ash: Effect of the SiO2/Na2O ratio.

$514 \quad$ Part I: FTIR study. Micropor. Mesopor. Mat. 106 (2007) 180-191.

515 [3] J. L. Provis, R. J. Myers, C. E. White, V. Rose, J. S. J. Van Deventer. X-ray microtomography shows pore

516 structure and tortuosity in alkali-activated binders. Cem. Concr. Res. 42 (6) (2012) 855-864.

517 [4] M. Criado, A. Fernandez-Jimenez, A.G. de la Torre, M.A.G. Aranda, A. Palomo. An XRD study of the

518 effect of the $\mathrm{SiO} 2 / \mathrm{Na} 2 \mathrm{O}$ ratio on the alkali activation of fly ash. Cem. Concr. Res. 37 (2007) 671-679.

519 [5] A. Palomo, S. Alonso, A. Fernandez-Jiménez. Alkaline activation of fly ashes : NMR study of the reaction

$520 \quad$ products,” J. Am. Ceram. Soc. 87(6) (2004) 1141-1145.

521 [6] M. Criado, A. Fernández-Jiménez, A. Palomo. Alkali activation of fly ash. Part III: Effect of curing conditions on reaction and its graphical description. Fuel. 89 (11) (2010) 3185-3192.

523 [7] M. Criado, A. Fernández-Jiménez, A. Palomo, I. Sobrados, J. Sanz. Effect of the SiO2/Na2O ratio on the 524 alkali activation of fly ash. Part II: 29Si MAS-NMR survey. Micropor. Mesopor. Mat. 109 (2008) 525-534.

525 [8] M. Keawthun, S. Krachodnok, A. Chaisena. Conversion of waste glasses into sodium silicate solutions. Int. $526 \quad$ J. Chem. Sci. 12(1) (2014) 83-91.

527 [9] M. Torres-Carrasco, J. G. Palomo, F. Puertas. Sodium silicate solutions from dissolution of glass wastes: Statistical analysis. Mater. Construcc. 64 (314), e014 http://dx.doi.org/10.3989/mc.2014.05213.

529 [10] L. K. Turner, F. G. Collins, “Carbon dioxide equivalent (CO2-e) emissions: A comparison between 
Manuscript submitted to:

Cement and Concrete Research

geopolymer and OPC cement concrete," Constr. Build. Mater. 43 (2013) 125-130.

[11] M. Torres-Carrasco, F. Puertas. Waste glass in the geopolymer preparation. Mechanical and microstructural characterisation. J. Clean. Prod. 90 (2015) 397-408.

533 [12] F. Puertas, M. Torres-Carrasco. Use of glass waste as an activator in the preparation of alkali-activated slag. Mechanical strength and paste characterisation. Cem. Concr. Res. 57 (2014) 95-104.

535 [13] C. Bobirică, J.-H. Shim, J.-H. Pyeon, J.-Y. Park. Influence of waste glass on the microstructure and strength of inorganic polymers. Ceram. Int. 41(10) (2015) 13638-13649.

[14] R. F. Farrell, S. A. Matthes, A. J. Mackie. A simple, low-cost method for the dissolution of metal mineral samples in plastic pressure vessels. University of Michigan (1980).

[15] D. D. Eberl. User Guide to RockJock- A program for determining quantitative mineralogy from X-ray

541 [16] J. Klinowski. Nuclear magnetic resonance studies of zeolites. Prog. NMR Spectrosc. 16 (1984) 237-309.

542 [17] M. Safiuddin, N. Hearn. Comparison of ASTM saturation techniques for measuring the permeable porosity of concrete. Cem. Concr. Res. 35(5) (2005) 1008-1013.

[18] M. Shubaeva, S. Izmailova, I. Karetina, S. Khoshchev. Synthesis and some adsorption properties of ZSM-3 Zeolite. Kinet. Catal. 33 (1992) 191-193.

[19] E. Flanigen, R. Grose. Phosphorous Substitution in Zeolite Frameworks. Adv. Chem. 101 (1971) 76-101.

[20] U. Hakkansson, L. Faelth, S. Hansen. Structure of high-silica variety of Zeolite-Na P. Acta Crystallogr. 46C (1990) 1363-1364.

[21] I. Hassan, H. D. Grundy. Structure of Basic Sodalite. Acta Crystallogr. 39C (1983) 3-5.

J. E. G. Hernandez, J. S. N. del Pino, M. M. G. Martin, F. H. Reguera, J. A. R. Losada. Zeolites in pyroclastic deposits in southeastern tenerife (Canary Islands). Clays Clay Miner. 41(5) (1993) 521-526.

C. Baerlocher, W.M. Meier. Crystal-Structure of Synthetic Zeolite Na-P1, an isotype of Gismondine. Zeitschrift fur Kritallographie, 135 (1972) 339-354.

[24] R. M. Barrer, J. W. Baynham, F. W. Bultitude, W. M. Meier. Low-temperature crystal growth of aluminosilicates, and some Gallium and Germanium analogues. Hydrothermal Chem. Silic., 1959.

[25] K. Seff, D. P. Shoemaker. The structures of zeolite sorption complexes. I. The structures of dehydrated zeolite 5 A and its iodine sorption complex. Acta Crystallogr. 22(2) (1967) 162-170. 
Manuscript submitted to:

Cement and Concrete Research

558 [26] H. Rahier, W. Simons, B. Van Mele, M. Biesemans. Low-temperature synthesized aluminosilicate glasses Part III influence of the composition of the silicate solution on production, structure and properties. $J$. Mater. Sci. 32(9) (1997) 2237-2247.

561 [27] I. Garcia-Lodeiro, A. Fernández-Jimenez, P. Pena, A. Palomo. Alkaline activation of synthetic aluminosilicate glass. Ceram. Int. 40(4) (2014) 5547-5558.

563 [28] M. E. Davis, R. F. Lobo. Zeolite and molecular sieve synthesis. Chem. Mater. 4(4) (1992) 756-768.

564 [29] J. L. Provis, G. C. Lukey, J. S. J. Van Deventer. Do geopolymers actually contain nanocrystalline zeolites? A reexamination of existing results. Chem. Mater. 17(12) (2005) 3075-3085.

566 [30] P. A. Jacobs, E. G. Derouane, J. Weitkamp. Evidence for X-Ray-amorphous Zeolites. J. Chem. Soc. Chem. Commun. (1981) 591-593.

568 [31] F. Schuth, K. S. W. Sing, J. Weitkamp, Handbook of Porous Solids Vol 1. Weinheim: Wiley-VCH (2002).

569 [32] P. Duxson, J. L. Provis, G. C. Lukey, F. Separovic, J. S. J. Van Deventer. Si NMR Study of Structural $570 \quad$ Ordering in Aluminosilicate Geopolymer Gels. Languimir. 21(7) (2005) 3028-3036.

571 [33] G. Engelhardt, D. Michel. High-resolution solid-state NMR of silicates and zeolites. Wiley (1987).

572 [34] K.J.D. MacKenzie, I. W.M. Brown, R. H. Meinhold, M. E. Bowden. Outstanding Problems in the Kaolinite573 Mullite Reaction Sequence Investigated by 29Si and 27Al Solid-state Nuclear Magnetic Resonance: I, 574 Metakaolinite. J. Am. Ceram. Soc. 68 (6) (1985) 293-297.

575 [35] J. Davidovits. Geopolymer-Chemistry and Applications. 3rd Ed. Saint-Quentin: Institut Geopolymere $576 \quad(2011)$

577 [36] P. Duxson, G. C. Lukey, J. S. J. van Deventer. Nanostructural design of multifunctional geopolymeric materials. Advances in Ceramic Matrix Composites XI Proceedings of the 107th Annual Meeting of the American Ceramic Society. (2012) 203-214. 